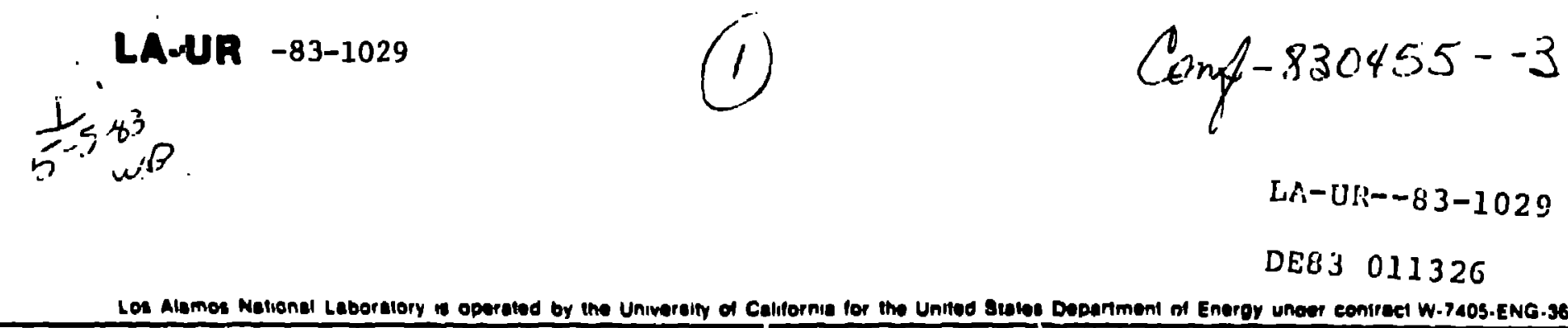

TITLE: SPIN-GLASS DYNAMICS DETERMINED FROM MUON SPIN-RELAXATION AND NEUTRON SPIN-ECHO MEASURMENTS

AUthoR(S). R. H. Heffner, M. Leon, and D. E. Maclaughlin

SUBMITTED to Proceedings of the Yamada Con $F$. on Muon Spln Rotation and Assoclated Problems, Shimoda, Japan, April 18-22, 1983

\title{
DISCI AIMER
}

This reporrl was prepared as ill account of work sponswred by an agency of the United States Governnient. Neither the Inited Stalcs (iovernment nor any apency thereof, nor any of theit employees, makes uny whrennly. express ur implied, or assumen uny legul liability or responalbility for the uccurncy. cuinpleteness, or unefulness isl' any information. appuratus, product, or mowesn diwelowed, ur tepresents that its use would thot infringe privately owned righta. Reference herein lo uny speciflc commereial producl, procens, or service by trade nume, trademark,

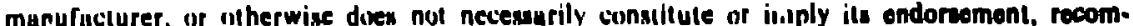
mendution, or fuvoring hy the United silutes (iovernment of any agency thereof. The viewn and opinions of authors expressed herein do not necessurily state or reflect thoae of the IInited Sitates finvernument or uny uxency thereol. 
SPIN-GLASS DYNAMICS DETERMINED FROM MUON SPIN-RELAXATION

AND NEUTRON SPIN-ECHO MEASUREMENTS

R. H. Heffner and M. Leon

Los Alamos National Laboratory

Los Alamos, New Mexico 87545 USA

and

D. E. MacLaugh11n

University of California

Rivers1de, California 92521 USA

\begin{abstract}
Muon spin-relaxation (uSR) and neutron spin-echo (NSE) measurements of magnetic-ion correlation times and correlation functions in the spin-glass systems CuMn, AgMn, and AuFe are compared. It 18 found that the $\mu S R$ and NSE measurements are in excellent agreenent both above and below the spin-glass freezing temperatures. The experimental results are compared to recent theories of spln-glass dynamics.
\end{abstract}

I. INTRODUCTION

Two new experimental techniques have been developed which show great promise in elucidating the nature of the spin dynamics in magnetic systems: neutron spin echo (NSE) 1 and muon opin relaxation ( $\mu S R), 2,3$ In this paper we compare measurements of the spin autocorrelation function in spin-glass systems CuMn and AgMn using the NSE and $\mu S R$ techniques. Where 
applicable, the results of these measurements are compared with recent mean-field theories of spin-glass dynamics. ${ }^{4}$

NSE measurements can be used to derive the spin correlation function of a magnetic system $S(q, t),{ }^{1}$ where $q$ and $t$ are the momentum transfer and time varlables, respectively. The $\mu S R$ technique is sensitive to a broad average over all $\mathrm{q}$, however, much like NMR. Moreover, neutron scattering is most effective 1 in measuring correlation times $(\tau) 10^{-12}<\tau<10^{-8} \mathrm{~s}$, whereas $\mu S R$ is most effective for $10^{-11}<\tau<10^{-4} \mathrm{~s}$. Thus, the techniques are compiementary.

II. MEASUREMENTS BELOW THE SPIN-GLASS FREEZING TEMPERATURE $T_{g}$ Recent measurements ${ }^{5}$ of the lorgitudinal-field dependence of the muon-spin-lattice relaxation rate $\lambda_{n}$ in spln glass AgMn show an algebralc form $\lambda_{\|}=K_{\omega_{\mu}}{ }^{v-1}$, for $0.3 \leq T / T_{g} \leq 0.9$. Here $\omega_{\mu}$ is the muon's Larmor frequency in the local plus applied fleld and $K$ is a constant depending on temperature. UEing very general arguments ${ }^{6}$ one may show that $\lambda_{1} \propto J\left(\omega_{11}\right)$, where $J(\omega):$ s the nolse powis of the fluctuating fleld, assuming that the applied fleld does not significantly affect the spin ciynamics (this assumption is tested below). A simplified form of the total spectral density $\mathcal{J}(\omega)$ for a $q-1$ ndependent probe can be written as

$$
\tilde{J}(\omega)-A \delta(\omega)+K_{1} J(\omega)
$$

The first term gives the static, the second the dynamic mode density. Taking the Fourler transform of $J(w)$ yields the local-field. autocorrelation function $S(t)$ : 


$$
\begin{aligned}
S(t) & =\int_{-\infty}^{\infty} e^{1 \omega t \mathcal{J}(\omega) \mathrm{d} \omega,} \\
& =A+B F(t)
\end{aligned}
$$

The constants $A$ and $B$ are temperature dependent and tireir sum must equal one. For $\omega<\omega_{e}$, the exchange frequency, $J(\omega) \propto \omega^{\nu-1}$, and therefore $F(t)$ is $\simeq\left(\omega_{e} t\right)^{-\nu}$ for $t \gg \omega_{e}^{-1}$; for $t \ll\left\langle\omega_{e}^{-1}\right.$ we require $F(t) \simeq 1$. The thrust of our comparison of the $\mu S R$ and NSE data below $T_{g}$ should now be clear: the $\mu S R$ data can provide $j(\omega)$, from which $S(t)$ can be derived for comparison with the NSE results averaged over $q$.

The $\mu$ SR results ${ }^{5}$ for $A g_{1-x} \mathrm{Mn}_{x}$ with $x=1.6,3$, and 6 at. $\%$ at applled flelds between 0.15 and $5.0 \mathrm{k} 0$ e yield $\nu=0.54 \pm 0.05$, for $0.3<\mathrm{T} / \mathrm{T}_{8}<$ 0.7 , and $\nu=0.24 \pm 0.02$, for $T / T_{B} \simeq 0.9$. The coefficlent B in Eq. (2b) can be roughly determined from fits to the $\mu_{S R}$ data $\left(\lambda_{\|}=K_{\omega_{\mu}}^{\nu-1}\right)$ if we take ${ }^{3} \lambda_{1} \approx 4 a_{0}{ }^{2} J\left(\omega_{11}\right)$. (Th1s expression, strictly applicable only in zero applied fleld, relates $\lambda_{\|}$to the known ${ }^{3}$ dipolar-fleld distribution $\Lambda$, averaged over all muon sites. Here, $\Delta=a_{0} / \gamma_{\mu}$, where $\gamma_{\mu}$ is the ruon gyromagnet1c rat10.) Although this procedure ylelds quite reasonable values of $B(0<B<1)$ for $v<1 / 2$ (see discussion below for theoretical constraints on $v$ ), it is not precise enough to constraln $B$, which is therefore taken to be a free parameter in fitting the NSE data.

\footnotetext{
"In this paper, we assume that the statistical properties of the magnetic-ion-spin fluctuations (which are measured by NSE) are approximately the same as tile resulting fluctuations of the dipolar field at the $\mu^{+}$olte.
} 
Figure 1 shows the NSE results ${ }^{1,7}$ of Mezel et al. In CuMn (5 at. \%, $\left.T_{B}=27.5 K\right)$. The solid curves are plots of Eq. (2b) with $F(t)=\left(\omega_{e} t\right)^{\nu}$. In the top cirve at $T / T_{B}=0.18$ we take $A=0.95$ and $B=0.05$, 1.e., very 11ttle fluctuating amplitude. The next curve at $\mathrm{T} / \mathrm{T}_{\mathrm{g}}=0.73$ is for $\mathrm{A}=$ 0.66 and $B=0.34$, and the bottom two curves at $T / T_{g}=1.1$ are for $A=0$ and $B=1$, 1.e., no static component at all. A reasonable mean-field estimate for $\omega_{e}$ is $i w_{e}=\mathrm{kT}_{g}$, yielding $\omega_{e}=3.6 \times 10^{12} \mathrm{~s}^{-1}$. As seen in F1g. 1, we have obtalned excelleat fits to the NSE data using $\omega_{e}=1.5 x$ $10^{12} \mathrm{~s}^{-1}$, close to the expected value, and the same values of $v$ as found from the $\mu S R$ data for $\lambda_{\|}$in AgMn described above. Note in particular that both the NSE and $\mu S R$ measurements show $\nu=0.24$ at temperatures near $T_{g^{\circ}}$ The excelient agreement between the two probes 1ndicates that: (1) the $q$-independent $S(t)$ found in NSE for a small range of $q\left(0.045 \AA^{-1}\right.$ to $0.36 \AA^{-1}$ ) evident ly holds over the wider range to which $\mu S R$ is sensitive, (2) the form of $J(\omega)$ determined from $u S R$ is evidently unaffected by applied Fields < $5 \mathrm{kOe}$ up to $\mathrm{T} / \mathrm{T}_{8} \approx 0.9$, and (3) 1dentlcal forms for $\mathrm{S}(\mathrm{t})$ are obralned for $\tau<10^{-9} \mathrm{~s}$ (NSE) and $\tau>10^{-9} \mathrm{~s}(\mu \mathrm{SR})$.

Recently, Sompolinsky and Zippelius have reported 4 a spin-glass correlation function which decays as $t^{-v}$, in agreement with both the uSR and NSE results. This theury predicts $v(T)<1 / 2$ at $T<\mathrm{T}_{g}$, but $v\left(\mathrm{~T}_{\mathrm{g}}\right)=$ 1/2. Thus theory and experiment agree below $T_{g}$, but not at $T=T_{B}$.

\section{MEASUREMENTS ABOVE $\mathbf{T}_{\mathbf{8}}$}

The spin-glass correlation function changes ${ }^{1}$ above $T_{g}$, eventually tending to an exponential well above $T_{g}\left(T / T_{g}>5\right)$. For a resonance probe like $\mu S R$ in a rapidly fluctuating environinent which exhihics a 
nonexponential $S(t)$, one may only define an effective correlation time $\tau_{\text {eff }}$ by 6

$$
\tau_{\text {eff }}=\int_{0}^{\infty} S(t) d t / \int_{0}^{\infty} S(0) d t
$$

The values of $\tau_{\text {eff }}$ in the AgMn, CuMn, and AuFe spin-glass systems have been obtained $^{2,3}$ from zero-field $\mu S R$ measurements above $T_{g}$. A pl th of these data is reproduced from Ref. 3 in Fig. 2.

Meze $1^{7}$ has fit the $S(t)$ obtained from NSE above $T_{g}$ to the following functional form:

$$
S(t)=\frac{1}{E_{m}} \int_{0}^{E_{m}} e^{-t / \tau} d E,
$$

where $\tau=\tau_{0} e^{E / T}$. For 5 at. \% CuMn, Mezel finds $E_{m}=300 \mathrm{~K}$ and $\tau_{0}=6 x$ $10^{-14} \mathrm{~s}$. Using these parameters and Eqs. (3) and (4) ylelds the solld curve In F1g. 2 for $T_{\text {eff }}$ vs. T. There is reasunable agreement between the $\mu \mathrm{SR}$ and NSE measurements, with no adjustable parameters. A simflar comparison by Uemura ${ }^{8}$ has been made Independently.

IV. CONCLUSION

Muon spin relaxation and NSE techniques give consistent results both above and below the freezing temperature in simple apin glasses. These results tend to confirm recent theorles ${ }^{4}$ of spln-glass dynamics below the freezing temperature $\left(T / T_{g}<0.7\right)$, but indicace a contradiction at $T \propto T_{g}$. This departure from theory should stimulate further experimental and theoretical work in this exclting area. 
We are grateful to D. L. Huber and R. E. Walstedt for stimulating discussions. This work was performed under the ausptces of the U.S. Department of Energy, and was also supported by the U.S. National Sclence Foundation, Grant No. DMR-8115543.
\end{abstract}

\title{
REFERENCES
}

[1.] F. Mezei and A. P. Muran1, J. Magn. Magn. Mat. 14 (1979) 211.

[2.] Y. J. Uemura, T. Yamazak1, R. S. Hayano, R. Naka1, and C. Y. Huang, Phys. Rev. Lett. 45 (1980) 583.

[3.] R. H. Heffner, M. Leon, M. E. Schillac1, D. E. MacLaughl1n, and S. A. Dodds, J. A.ppl. Phys. 53 (1982) 2174.

[4.] H. Soripolinsky and Annette Z1ppelius, Phys. Rev. B25 (1982) 6860.
[5.]R. H. Hef $\approx$ ner, D. W. Cooke, M. Leon, M. E. Sch1llac1, D. E. Maclaughifn, and L. C. Gupta, paper contributed to this conference.

[6.] A. Abragam, Principles of Nuclear Magnetism (Clarendon Press, Oxford, 1s61).

[7.] F. Mezel, invited talk, 28th Conference on Magnetism and Magnet1c Materials, Montreal, Canada, 1982, to be published in J. App 1. Phys.

[8.] Y. J. Uemura, Ph.D. thesis, University of Tokyo, 1981, unpublished. 
FIGURE CAPTIONS

Fig. 1. Neutron spin echo spin-correlation function in CuMn (5 at.\%) vs logarithm of time in seconds (Ref. 1). Three sets of data are shown (from top to bottom): $\mathrm{T} / \mathrm{Tg}=0.18,0.73$, and 1.10 . Solid curves are from Eq. (2b) with $F(t)=\left(\omega_{e} t\right)^{-v}$, using values of $v$ obtained from $u S R$ data (Ref. 5), and values of $A$ and $B$ as described in the text.

Fig. 2. Effective correlation time $\tau_{\text {eff }}$ vs temperature as determined from zero-field $\mu$ SR data (Refs. 2 and 3). Solld curve is from Eqs. (3) and (4) using parameters determined by neutron spin echo measurements (Ref, 7). 


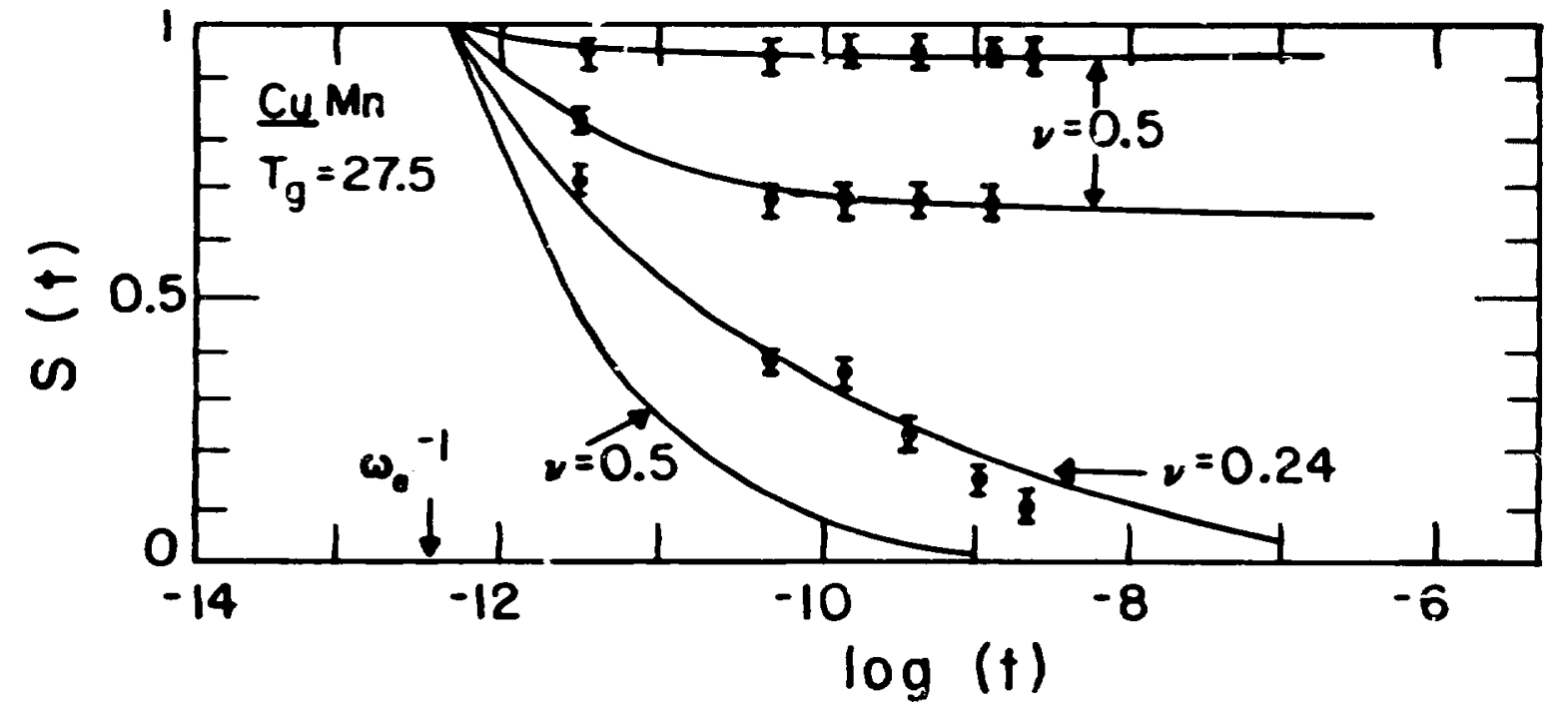

Figure 1 


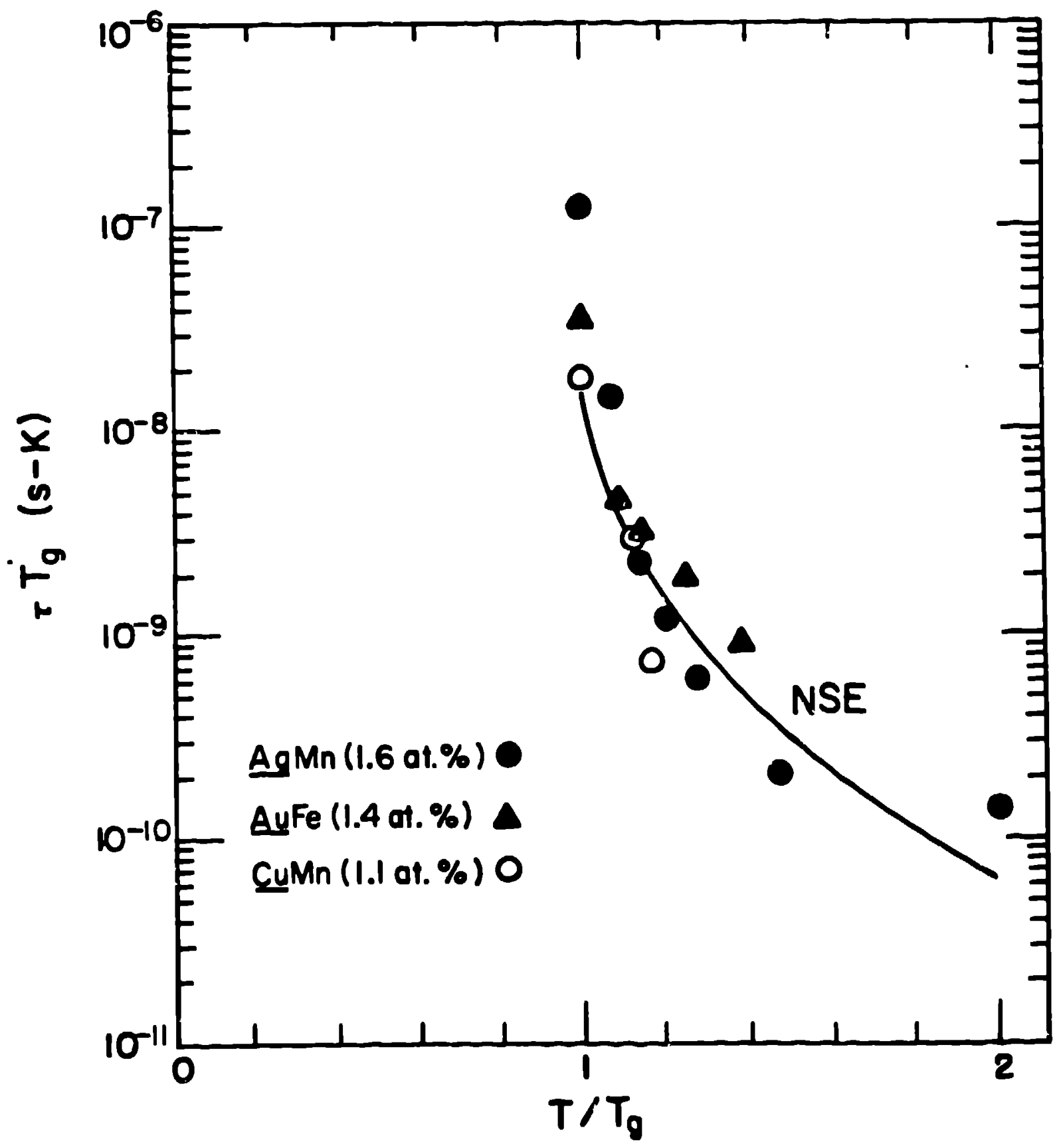

F1gure 2 